The University of San Francisco

USF Scholarship: a digital repository @ Gleeson Library |

Geschke Center

January 2012

\title{
Metamodel for Service Analysis and Design Based on an Operational View of Service and Service Systems
}

Steven Alter

University of San Francisco, alter@usfca.edu

Follow this and additional works at: http://repository.usfca.edu/at

Part of the Business Administration, Management, and Operations Commons, Management Information Systems Commons, and the Technology and Innovation Commons

\section{Recommended Citation}

Alter, Steven, "Metamodel for Service Analysis and Design Based on an Operational View of Service and Service Systems" (2012). Business Analytics and Information Systems. Paper 28.

http://repository.usfca.edu/at/28 


\title{
METAMODEL FOR SERVICE ANALYSIS AND DESIGN BASED ON AN OPERATIONAL VIEW OF SERVICE AND SERVICE SYSTEMS
}

\begin{abstract}
This paper presents a metamodel that addresses service system analysis and design based on an operational view of service that traverses and integrates three essential layers, service activities, service systems, and value constellations. The metamodel's service-in-operation perspective and underlying premises diverge from a view of service systems as systems of economic exchange that has appeared a number of times in the journal Service Science.

In addition to the metamodel itself, this paper's contributions include an explanation of eight premises on which it is based plus clarifications concerning concepts such as service, service system, customer, product/service, co-production and co-creation of value, actor roles, resources, symmetrical treatment of automated and non-automated service systems, and the relationship between servicedominant logic and service systems. Many articles have discussed these topics individually. Few, if any, have tied them together using an integrated metamodel.
\end{abstract}

Keywords: service science, service system, work system, service system metamodel

\section{Need for Usable, Design-Oriented Models}

Building upon previous developments in services marketing, service operations, and economics, the recent initiative to develop a science of service has generated many service-related academic programs and many articles, white papers, several books, and the new journal Service Science. At this early stage in the development of service science, leading proponents have concluded that "Service Science is built on top of the Service Dominant Logic (SDL) worldview, (Spohrer and Maglio 2009; Vargo and Lusch 2004a)" (Spohrer et al. 2010, p. 4), whereby the essence of service systems involves arrangements, negotiations, and competition in the context of economic exchange. The SDL worldview deals with many fundamental topics, but its focus and level of analysis are distant from everyday operational issues that are intertwined with service system analysis, design, and innovation. For example, Grönroos (2011) dissects the concepts of value creation and value co-creation in depth and proposes significant revisions to some of the foundational premises of SDL. Regarding one central idea, he concludes that foundational premise \#6, "the customer is always a co-creator of value," is misleading even though it is "repeated over and over again in the literature." (p. 292). Searching for synergies between SDL and the operational view of service systems emphasized in this paper, Alter (2010d) concludes that those two views seem like second cousins with some commonalities but little familiarity. Overall, it is possible that premature closure regarding the centrality of SDL as the foundation of service science might delay the development of service science by taking for granted a highly abstract approach that is difficult to use in real world situations.

This paper proposes a different approach that facilitates description and analysis of service systems from a management viewpoint. This approach also provides a basis for more detailed descriptions required to build software support for services in operation. The proposed approach links a simple definition of service with a straightforward definition of service system that can be represented at different levels of granularity. This paper applies those definitions in a metamodel of service-in-operation that provides a direct path for addressing issues that must be resolved in moving from the general concept

(c) Steven Alter 2012. A subsequent version was published by Service Science, 4(3), pp. 218-235. 
of a service to the details of service systems. The metamodel is only partially consistent with the economic exchange model because it focuses on service systems in operation, is on a different level of analysis, and uses some terms differently. (A metamodel is a summary of relationships between concepts for producing conceptual models of specific situations in a domain. For example, the inclusion of the concepts "informational entity" and "actor role" in the metamodel implies that a conceptual model of a specific service system should identify informational entities and actor roles within that specific system.) This paper's alternative view of basic service science concepts can be used to support analysis and design for service systems, including decomposition of service systems during analysis and design efforts.

Contribution. This paper's primary contribution is a metamodel for describing service systems. To highlight the differences between this paper's approach and existing approaches that emphasize economic change, this paper identifies eight underlying premises that express a distinct perspective related to service and service systems. Those premises help in clarifying other views of service and service systems. They are the basis of an integrated metamodel that spans three levels of concern within service science: service activities, service systems, and value constellations, thereby extending an earlier metamodel (Alter 2010a) developed to provide an integrated view of social and technical aspects of work systems. By spanning three levels of analysis, the metamodel articulates a cohesive view of topics that are usually discussed separately, and often in a highly abstract way that is difficult to operationalize when analyzing or designing service systems. Consistent with Grönroos (2011), the metamodel views co-production/cocreation of service as an optional feature of service systems rather than as a defining characteristic of service in general. Its integrated view of sociotechnical service systems and completely automated service systems supports decomposition of sociotechnical systems into smaller sociotechnical subsystems and totally automated subsystems, an essential issue in designing IT-enabled service systems. Overall, the metamodel's integrated view of value constellations, service systems, and service activities could facilitate service analysis and design processes. Its specificity and clarity related to basic terms may contribute more directly to service system analysis and design than some of the theoretical literature's distinctions related to the nature of service, service systems, economic exchange, and value propositions.

Organization. The next section explains eight premises that are the basis of the metamodel. These premises form a unique perspective related to service science topics such as the definition of service and service system, co-production/co-creation of value, service-dominant logic, and value constellations. The coverage of the metamodel explains its structure, uses an example to illustrate its potential application, and describes how it is related to typical service science topics. The discussion and conclusion sections explain more about the nature of this paper's contribution and the potential usefulness of the metamodel.

\section{Eight Premises Related to Services and Service Systems}

Consider everyday services and service systems such as entertainment services, Internet service provision, plumbing services, transportation services, medical services, rental services, postal services, web services, and software development. Surprisingly, some of those services do not fit commonly cited definitions or characteristics of service. For example, a plumber's work is not intangible and often is not experienced directly by a customer who is elsewhere. A vaccination transfers ownership of a physical thing. Subway service is neither customized nor subject to negotiation between provider and customer. Also, the emphasis on economic exchange in SDL is only tangentially useful for analyzing central aspects of medical and transportation services, where economic exchange is often far removed from direct interactions between providers and customers. Similarly for web services, where the provider and customer are computerized entities.

This section identifies eight premises that are the basis of the service system metamodel presented later. These premises are directly related to the nature of services and service systems, but overlap only partially with the perspectives and definitions of service, service system, and related concepts in the nascent service science literature. Specification of these premises illustrates alternatives to stated or unstated premises that inform views of service science that are sometimes taken for granted. Underlying 
this paper's approach is the assumption that unlike genomics or astrophysics, the potential impact of service science depends on providing straightforward concepts and principles that are understandable to typical university students and business professionals while also supporting complex analysis at a high level of sophistication wherever that is genuinely needed.

\section{1) Service science should cover the full gamut of service-related situations.}

The full gamut of service-related situations ranges from simple everyday services to complex service systems that serve entire societies. Ideally, service science should cover every type of activity that most people consider services, including:

- services for external customers and for internal customers;

- $\quad$ automated, IT reliant, and non-automated services;

- customized, semi-customized, and non-customized services;

- personal and impersonal services;

- repetitive and non-repetitive services;

- highly interactive services and services with very little interaction;

- long-term and short-term services;

- services with varying degrees of self-service responsibilities.

Even a cursory look at the service science literature would reveal that many articles about service science exclude some of those situations, either implicitly or explicitly. Discussions of service that emphasize the nature of economic competition tend to focus on service for external customers and tend to ignore service for internal customers, such as payroll, HR, and internal consulting services. Views of service that assume the essence of service is about service interactions between people tend to ignore highly or totally automated services. Other views of service assume that service is essentially personal and usually customized, contrary to the essence of a number of the services mentioned above. Ideally, the service science definition of service and service system should cover every type of service situation.

\section{2) Services are acts performed for others.}

Service science currently lacks a commonly agreed-upon, readily usable definition of service that applies to almost all situations that most business professionals, computer scientists, and other researchers would consider services. Existing definitions of service include, among others:

- "Any act or performance that one party can offer to another that is essentially intangible and does not result in the ownership of anything." (Kotler and Keller 2006).

- "A provider-client interaction that creates and captures value" (IBM Research 2012).

- "A time-perishable, intangible experience performed for a customer acting in the role of a coproducer" (Fitzsimmons and Fitzsimmons 2006).

- A process in which "the customer provides significant inputs into the production process." (Sampson and Froehle 2006).

- "A change in the condition of a person, or a good belonging to some economic entity, brought about as a result of some other economic entity, with the approval of the first person or economic entity" (Hill 1977).

- "The application of specialized competences (knowledge and skills) through deeds, processes, and performances for the benefit of another entity or the entity itself. (Vargo and Lusch 2004a).

- "Service is value-creating support to another party's practices. As suggested by Normann (2001), this support may either relieve customers from taking on some task or enable them to do something that otherwise would not be possible to accomplish or would be accomplished less efficiently or effectively." (Grönroos 2011)

- $\quad$ A service is generally implemented as a course-grained, discoverable software entity that exists as a single instance and interacts with applications and other services through a loosely coupled (often asynchronous), message-based communication model.” (Brown et al. 2005). 
We adopt a simple, dictionary-like definition of service from Alter (2008b; 2010c). "Services are acts performed for others, including the provision of resources that others will use." To provide symmetrical treatment for human and automated services for people and services performed by one automated entity for another (such as Web services), a more general version of the definition is "Services are acts performed for other entities including the provision of resources that other entities will use."

Both versions of our definition are consistent with the idea in Ramirez (1999) that customer value includes labor saving value and enabling value. It applies to the three types of value configurations discussed by Stabell and Fjeldstad (1998), value chains, value networks, and value shops. It covers special cases such as self-service and automated services for people. In self-service, service providers provide resources that are used by customers performing self-service activities, whereby the service is the provision of resources, not the self-service activities. In automated services for people, machines perform the service activities. Both versions of the definition are consistent with most of the definition in Vargo and Lusch (2004a), except that our definition stipulates that services are acts performed for others. Thus, activities performed only for one's own benefit, such as cleaning one's own office or climbing a mountain, are not considered services unless those acts are performed in order that someone else will benefit.

\section{3) Every economic activity is a service.}

With our definition of service, any economic activity is a service because it involves purposeful action performed for the benefit of someone else (or something else, in the case of programs operating under service computing). Focus on services is still useful when thinking about almost any system in a business because it highlights service metaphors and characteristics often associated with service. Of special value are the numerous service-related design dimensions (Alter 2010d) that are potentially important but often overlooked when trying to design or evaluate systems in organizations, such as the extent of customer responsibility for service activities, the extent of co-production, and the extent to which activities are front stage or back stage.

By assuming that every purposeful action performed for the benefit of others is a service, our definition bypasses the longstanding inability to distinguish between products and services in a way that is genuinely valuable for designing service systems. Instead, the definition accepts the foundational premise from SDL that "goods are distribution mechanisms for service provision" (Vargo and Lusch 2004a), according to which distinctions between products and services may not be fundamental for understanding how value is delivered. If a service is an act performed for others, then the production of physical things can be viewed as services. Consistent with Vargo and Lusch (2004b), our definition of service does not rely on characteristics often associated with service, such as intangibility, customization, simultaneity of production and consumption, time-perishability, or involvement of customer interactions or experiences.

Several other implications of our definition are noteworthy. First, the most direct recipients of services may not perceive their value. For example, a student may not perceive the value of a classroom exercise; an addicted individual may not perceive the value of a treatment; a taxpayer may not perceive the value of tax-related services by tax agencies. These examples illustrate that most service systems have multiple types of customers with disparate or even conflicting interests. In addition, since laws and ethical codes differ from place to place and time to time, an assumption that services must be legal or ethical would imply that a lawyer or ethicist might be required to determine whether something is a service.

\section{4) Product vs. service is best viewed as a set of design dimensions, not a simple dichotomy.}

In relation to service analysis and design in real world situations, definitional distinctions between products and services are much less important than design characteristics that are continuous variables on dimensions ranging from product-like to service-like. In this context, product-like implies a greater concentration of characteristics often associated with products, such as tangibility, durability, and ownership, whereas service-like implies a greater concentration of characteristics associated with services. An offering typically viewed as a product may have many service-like features, and vice versa. 
Consider a series of related educational offerings: a traditional textbook, an online version, an online version with interactive exercises, an online version with interactive exercises and interaction with an expert, and, finally, an interactive person-to-person tutorial by an instructor. Each successive modification transforms the product-like book into something that is more service-like until the last approach is clearly a service. Similarly, provisioning of meals can be made more product-like by moving toward prepackaged fast food meals; it can be made more service-like by moving toward a fine dining experience that still consists of tangible things delivered to customers. Many similar examples involve various forms of information distribution, medical care, and many kinds of work that are performed for customers.

Accordingly, it is unnecessary for the metamodel to differentiate between products and services. Instead, the metamodel gives the name "product/service" to anything that is produced by a definable activity in a service system. It treats an entire service system's products/services as whatever the service system's customers receive, use, and/or benefit from in a direct way. On the other hand, the metamodel recognizes characteristics that are often associated with products or services, such as commodity versus customized, tangible versus intangible, and personal versus impersonal. It treats such distinctions as continuous design dimensions, essentially characteristics of a specific product/ service.

The design dimension related to co-production of value is of special interest because co-production or co-creation of value is viewed as essential in SDL and is treated by Sampson and Froehle (2006) as a defining characteristic of service. From our viewpoint, it is more useful to follow Grönroos's (2011) view that co-creation of value is optional, and to recognize a continuum from minimal through extensive cocreation by the customer:

- The customer does nothing.

- The customer provides a request for service but does little else (minimal level of co-creation)

- The customer participates in parts of service fulfillment processes (beyond specifying requirements)

- The service occurs through multiple service interactions including direct participation by customers.

- A self-service approach is used, whereby the customer performs self-service processes and activities using resources provided by the service provider.

For understanding, analyzing, and improving specific product/service offerings, the interesting question is not whether value is co-produced, but rather the extent to which the customers are or should be coproducers or co-creators of value. The changes might move toward more co-creation or less. For example, customers who just want something to be done would try to minimize the extent of co-creation (e.g., services such as cleaning houses or shoveling snow). In contrast, customers who want to be involved might find ways to engage more directly with service providers whom they find interesting or inspiring.

\section{5) Service systems are work systems.}

We define service system as a work system that produces services, i.e., that performs acts for others, which may include producing physical things and/or information. The work system framework in Figure 1 identifies nine elements for understanding a work system. These elements constitute the core of a systems analysis method for business professionals called the work system method (Alter 2006; 2008a; 2008b).

A work system is a system in which human participants and/or machines perform processes and activities using information, technology, and other resources to produce products/services for internal or external customers. All work systems that produce something for the benefit of others are service systems whether or not economic exchange is involved (e.g., service systems directed internally within organizations). Placement of the customer at the top of the work system framework reflects the work system's goal of producing products/ services for customers, rather than just performing activities. All of the elements of the work system framework will be reinterpreted in the more detail-oriented service system metamodel explained later. The work system framework has proven effective at a summary level of understanding. Experience with hundreds of analyses based on the work system framework shows that the metamodel could be used as the basis of tools designed to clarify details that are not important at a summary level. 
Since a service system is a work system, the nine elements of even a basic understanding of a service system are the same as the elements for understanding a work system. Table 1 defines each of the nine elements of the work system framework as though they are elements of a service system. The remainder of this paper uses the term service system except where it is necessary to use the term work system as part of an explanation of the origin of the ideas.

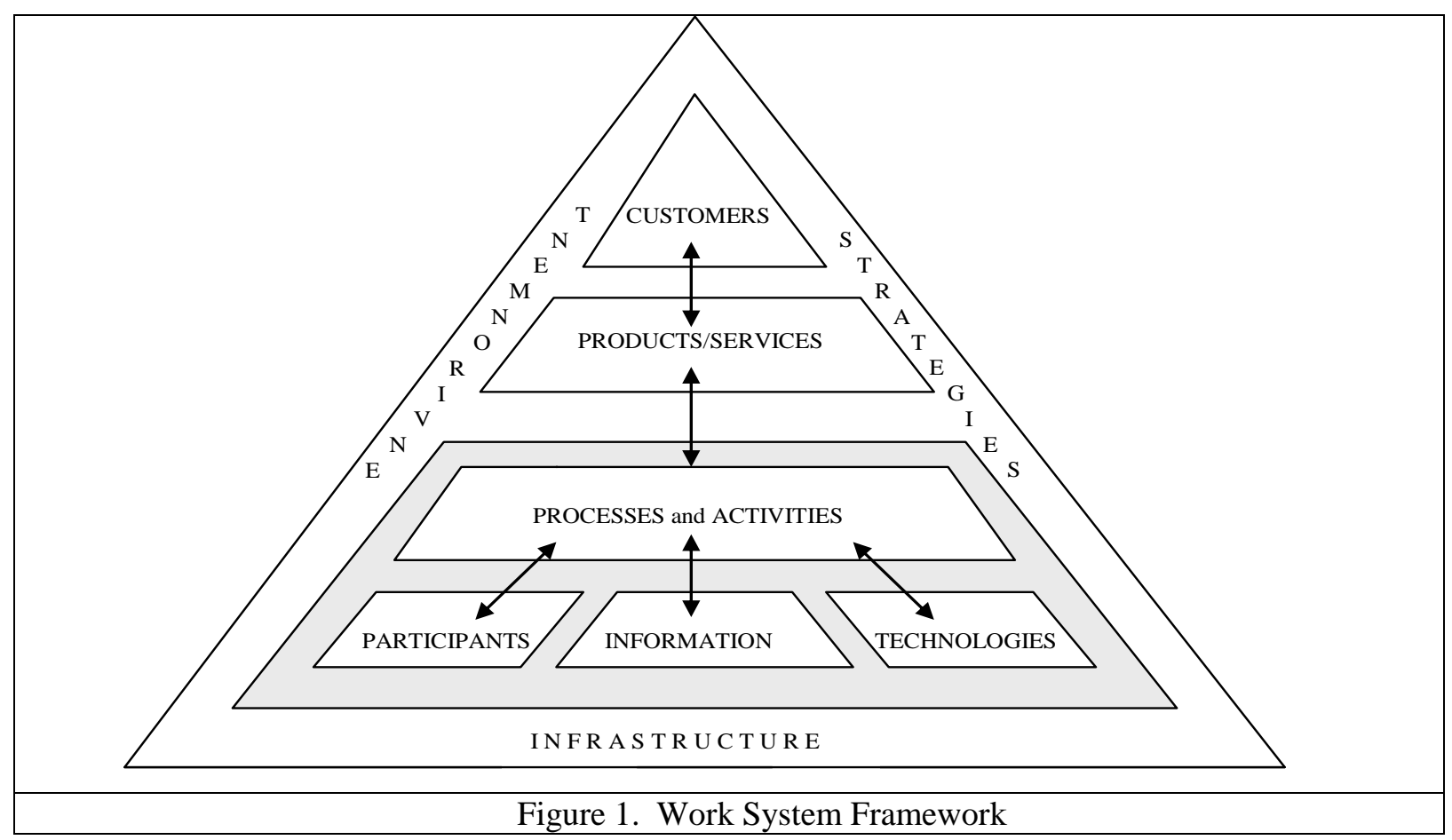

Table 1: Definitions of elements of a service system based on the work system framework and viewing a service system as a work system (based on Alter (2006; 2008a)

Customers. Customers are recipients of a service system's products and services for purposes other than performing provider activities within the service system. External customers are service system customers who are the enterprise's customers, whereas internal customers are service system customers who are employed by the enterprise, such as customers of the enterprise's service system for payroll. Customers of a service system may be active participants in the service system (e.g., patients in a medical exam, students in an educational setting, and clients in a consulting engagement). In other situations, customers request service activities and play no other role in the service system. The image of "the customer" is largely an illusion for many important service systems that have different customer types whose interests are different and possibly divergent, such as a medical service system that serves patients, but provides information for insurance companies, government agencies, and other external customers. The distinction between direct beneficiary and paying customer is important wherever service systems are evaluated, at least partially, by paying customers who are not service beneficiaries.

Products/services. Service systems exist to produce products/services for internal or external customers. The term product/service is used because outputs of most service systems exhibit a combination of product-like and service-like characteristics. Product/services are received and used by customers within the service system, within other service systems, or outside of the context of service systems (as when a service system's customers do not use its products/services for the benefit of others).

Processes and activities. The actions that occur within a service system are service activities. In some service systems those activities constitute a process because they have a clear sequence whose individual steps are performed using defined methods. Other service systems include service activities that may be performed in different ways and in different orders depending on the judgment of the participants. 
Activities within a service system are assumed to be the activities that actually occur, rather than the activities that are supposed to occur. These activities include workarounds that often become part of organizational routines (Feldman and Pentland 2003) when prescribed activities are too cumbersome to perform or cannot be performed due to inadequate resources or transient problems.

Participants. Participants are people who perform activities within a service system, including both users and non-users of IT. Failure to include participants and their characteristics in service system analysis and design automatically would omit important sources of variation in the results. Inclusion of the term participant instead of the term user avoids ignoring important participants who do not use computers and minimizes confusion from referring to stakeholders as users, whether or not they actually use the technology in a service system. Customers participate in service systems to differing extents.

Information. All service systems use and/or create information, which in the context of service systems can be expressed as informational entities that are used, created, captured, transmitted, stored, retrieved, manipulated, updated, displayed, and/or deleted by processes and activities. Typical informational entities include orders, invoices, warranties, schedules, income statements, reservations, medical histories, resumes, job descriptions, and job offers. Informational entities may contain other informational entities. For example, orders may contain line items and documents may contain chapters.

Technologies. Almost all significant service systems rely on technology, which may take on one of two operational forms, 1) tools that are used by service system participants and 2) automated agents, hardware/software configurations that perform totally automated activities. That distinction is crucial as service systems are decomposed into successively smaller subsystems, some of which are totally automated.

Environment. Factors in a service system's environment may have direct or indirect impacts on its performance, aspiration levels, goals, and requirements for change. A service system's environment includes the relevant organizational, cultural, competitive, technical, regulatory, and demographic environment within which the service system operates, and that affects the system's effectiveness and efficiency. Organizational aspects of the environment include stakeholders, policies and procedures, and organizational history and politics, all of which are relevant to the design of many service systems.

Infrastructure. Infrastructure includes relevant human, informational, and technical resources that are used by a service system but are managed outside of it and are shared with other service systems. From an organizational viewpoint, such as that expressed in Star and Bowker (2002), infrastructure can be subdivided into human infrastructure, informational infrastructure, and technical infrastructure, all of which can be essential to a service system's operation.

Strategies. Strategies are conscious allocations of resources to achieve goals. Strategy levels that are relevant to service systems include enterprise strategy, organization strategy, and service system strategy. In general, strategies at the three levels should be in alignment, and service system strategies should support organization and enterprise strategies. Unfortunately, strategies at any of the levels may not be articulated or may be inconsistent with reality or with beliefs and understandings of important stakeholders.

Our definition of service system overlaps with the definition in the glossary of the CMMI (Capability Maturity Model Integration) for Services, version 1.3 (Software Engineering Institute 2010): "an integrated and interdependent combination of component resources that satisfies service requirements. A service system encompasses everything required for service delivery, including work products, processes, facilities, tools, consumables, and human resources. Note that a service system includes the people necessary to perform the service system's processes."

In contrast to our definition, a number of service system definitions and related connotations in previous issues of Service Science rely more directly on concepts associated with SDL (Vargo and Lusch 2004a). 
- $\quad$ Service Science defines service as value co-creation phenomena that occur when service system entities interact according to value propositions that guide the application of competence for mutual benefit." (Spohrer et al. 2010).

- $\quad$ The foundations of service systems are: 1) a dynamic configuration of resources; 2) a set of value co-creation mechanisms between suitable entities; 3) an application of competencies-skillsknowledge of any person(s) in job or stakeholder roles; 4) an adaptive internal organization responding to the dynamic external environment; 5) learning and feedback to ensure mutual benefits or value co-creation outcomes. Thus "Service systems are open systems capable of improving: a) the state of another system through sharing or applying its resources; b) its own state by acquiring external resources" (Spohrer et al. 2010).

- $\quad$ The smallest service system centers on an individual as he or she interacts with others, and the largest service system comprises the global economy. Cities, city departments, businesses, business departments, nations, and government agencies are all service systems. Every service system is both a provider and client of service that is connected by value propositions in value chains, value networks or value-creating systems (Normann 2001)." (Maglio and Spohrer (2008), cited by Vargo and Akaka (2009))

The SDL approach to service systems tends to be quite abstract, focuses on economic exchange rather than business operations, and treats anything from an individual to the global economy as a service system (Alter 2011a). Concepts such as co-creation of value, value proposition, shared information, and reciprocal service provision sometimes seem overstated for everyday service systems such as those mentioned earlier. Also, assumptions about mutual benefit sometimes seem exaggerated, as in service situations with conflicting motives, ambiguous or intentionally misleading value propositions (e.g., advertising), information asymmetry, and where service beneficiaries are not paying customers and may have neither information nor decision rights for choosing among value propositions from different service providers. This paper's more operational definition of service system is easier to apply across a wide range of service situations. On the other hand, it does not try to address the challenge of characterizing the nature of economic exchange.

\section{6) Service system analysis and design should recognize conflicting stakeholder interests.}

Each of the typical services mentioned at the beginning of this section has multiple customer and stakeholder groups, often with conflicting perceptions of the need for and quality of various things produced by the service system. Thus, the frequently encountered concept of "the customer" is often insufficient for describing, designing, or evaluating service systems. It is more realistic to assume that sociotechnial service systems often have multiple customer groups and stakeholders whose interests may conflict.

At minimum, interests of customers often conflict with interests of providers because customers are most concerned with characteristics of whatever they receive from a service system (e.g., cost, quality, reliability), whereas providers are also concerned with the system's efficiency. While an idealized service system should provide excellent service in an internally efficient manner, organizing for internal efficiency may reduce responsiveness to customers and may increase their costs. For example, an organization's accounts payable system may be designed to maximize the efficiency of accounts payable clerks within the general constraint of paying the bills on time. From the viewpoint of that service system's customers, immediate payment upon receipt of the invoice would be more convenient and more profitable.

There also may be goal conflicts between different groups of customers. For example, an information system that provides up-to-the-minute operational results may satisfy top management's desire to have current information, but may cause problems for lower-level employees, who would rather be able to analyze their own operational results before having to respond to inquiries from managers who receive the same data at the same time. In contrast with that simple example, complex supply chains and complex service systems in society, such as water systems, transportation systems, and medical systems, have many different customer groups with significantly different concerns. 


\section{7) Service system analysis and design should recognize impacts of human intentions, capabilities, and variability on service quality.}

Service system designers and participants are humans whose intentions, capabilities, and performance variability may affect service quality in many important ways. Issues related to human variability, motivation, information asymmetry, moral hazard, workarounds, bricolage (making do with whatever is available), and emergent change abound in the organizational behavior and sociotechnical systems literature. Exceptional dedication and effort may generate outstanding results even with relatively poor resources; inattention and lackadaisical effort may lead to mediocre results even with the best resources; personal agendas may undermine service system designs regardless of the level of resources. Consequently, careful description, design, or evaluation of a service system should clarify underlying assumptions about service system participants because any of the following might describe reality:

- The relevant service systems are computerized entities that operate based on computer programs, and therefore do not have participants even though participants in other work systems created them and maintain them.

- Service system participants are dutiful components of service systems who will perform specified processes and activities consistent with designers' intentions and management's goals.

- Service system participants are fallible components of relatively fragile service systems that cannot control participants' activities directly, but only guide those activities through a combination of training, incentives, punishments, monitoring, and feedback. Service system participants may have personal agendas and goals that differ from explicit or implicit goals of service systems and their designers and owners.

\section{8) Service system analysis and design should recognize complementary systems within value constellations.}

Normann and Ramírez (1994) extended Porter's (1985) idea of value chain analysis with the concept of value constellation, where "value is coproduced by actors who interface with each other. They allocate the tasks involved in value creation among themselves and to others, in time and space, explicitly or implicitly. ... Co-producers constantly reassess each other, and reallocate tasks according to their own views of the competitive advantage they perceive each other to have." (p. 54) In service system terms, a value constellation is a combination of service systems that operates across different enterprises to satisfy customer needs. Unlike a supply chain whose basic structure follows a multi-layer bill of materials even if some of the suppliers may change, value constellations for services are assumed to exhibit occasional redefinition and reallocation of responsibilities as new players create new offerings that may replace or repackage existing activities. Extensions of that idea appear in various strategy-oriented discussions of value configurations, such as Stabell and Fjeldstad (1998) and Tapscott et al. (2000).

A given service system may be part of many different value constellations. For our purposes, a value constellation is a set of complementary service systems whose individual operation and interactions contribute to an identifiable type of service for an identifiable group of customers. The idea of value constellation is of great potential importance in service science because few if any firms can provide all resources that are needed to support value creation by their customers. Detailed attempts to locate service systems within value constellations would go beyond merely identifying outsourced or "out-tasked" activities. It would take more of a system view, and would focus on service system characterizations of both the value constellation itself and the various service systems that it includes.

\section{Metamodel for Service System Analysis and Design}

The service system metamodel in Figure 2 (Alter 2011b) is based on the eight premises above.

1) It covers the full gamut of service-related situations, including services for external customers and for internal customers; automated, IT-reliant, and non-automated services; customized, semi-customized, 
and non-customized services, and so on. It supports decomposition of sociotechnical service systems into smaller service systems, some of which may be totally automated.

2) It views services as acts performed for others (which might be other entities in the case of totally automated services).

3) It treats every economic activity as a service, even though that premise is not central to its purpose of representing operational service systems.

4) It views product vs. service as a continuum, not a dichotomy. It does that by including an entity type called product/service that has many design dimensions and other characteristics.

5) It treats service systems as work systems by defining many of its entity types as reinterpretations of elements of the work system framework (Figure 1).

6) It recognizes conflicting stakeholder interests by including service system environment, organization environment, and enterprise environment, each of which may include non-customer stakeholders along with culture, history, policies, competition, and other aspects of the surrounding environment.

7) It recognizes quality-related impacts of human intentions, capabilities, and variability by including an entity type called participant and assuming that attributes of participants include skills, knowledge, incentives, interests, and other characteristics that affect human action.

8) It views service systems as components of value constellations.

The service system metamodel in Figure 2 revises and extends a work system metamodel (Alter 2010a) that was developed to support more detailed analysis than is afforded by the work system framework. That framework is effective as the basis for preliminary analysis of IT-reliant service systems, but is less effective as a tool for more detailed analysis. The work system metamodel provided clarifications concerning topics such as why goals were not mentioned explicitly in the work system framework, how customers can be participants, the relationship between participants and users, and the possibility of largely symmetrical treatment of sociotechnical work systems and totally automated work systems. Each element of the work system framework is represented in the metamodel, although most are re-interpreted in a more detailed way. For example, information becomes informational entity, technology is divided into tools and automated agents, and activities are performed by one of three types of actors. As in the work system metamodel, the service system metamodel in Figure 2 uses shading to distinguish between re-interpretations of elements in the work system framework and other concepts that are not in the work system framework.

Entity types in the metamodel. Representation decisions in the metamodel attempt to maximize understandability while revealing potential omissions from a service system design process. The metamodel uses an icon for "composition" (see legend at the bottom of Figure 2) to identify elements that are likely to be decomposed into smaller elements in some analysis and design situations. It names relationships and uses the pointed end of "<" and " $>$ " to indicate the direction of relationships.

Each entity type in the metamodel has numerous attributes that are not shown in the metamodel but that might be shown in a second level in a more detailed representation (e.g., as attributes of a class in a UML class diagram). Many entity types have multiple goals, characteristics, metrics, and relevant principles that cannot be displayed in a one-page representation but could be included in a computerized representation that could be displayed based on a user's information needs. For example, attributes of a participant include various types of knowledge and skills, level of motivation, and incentives. An informational entity's attributes related to size, form, coding scheme (if any), precision, and accuracy depend on the type of informational entity (e.g., database or document). Most entity types have at least several goal attributes that may be mutually inconsistent in any specific situation. For example, the role non-customer participant may have a daily output goal but may also have other goals related to error rate, responsiveness to the service system's customers, or other aspects of quality. 


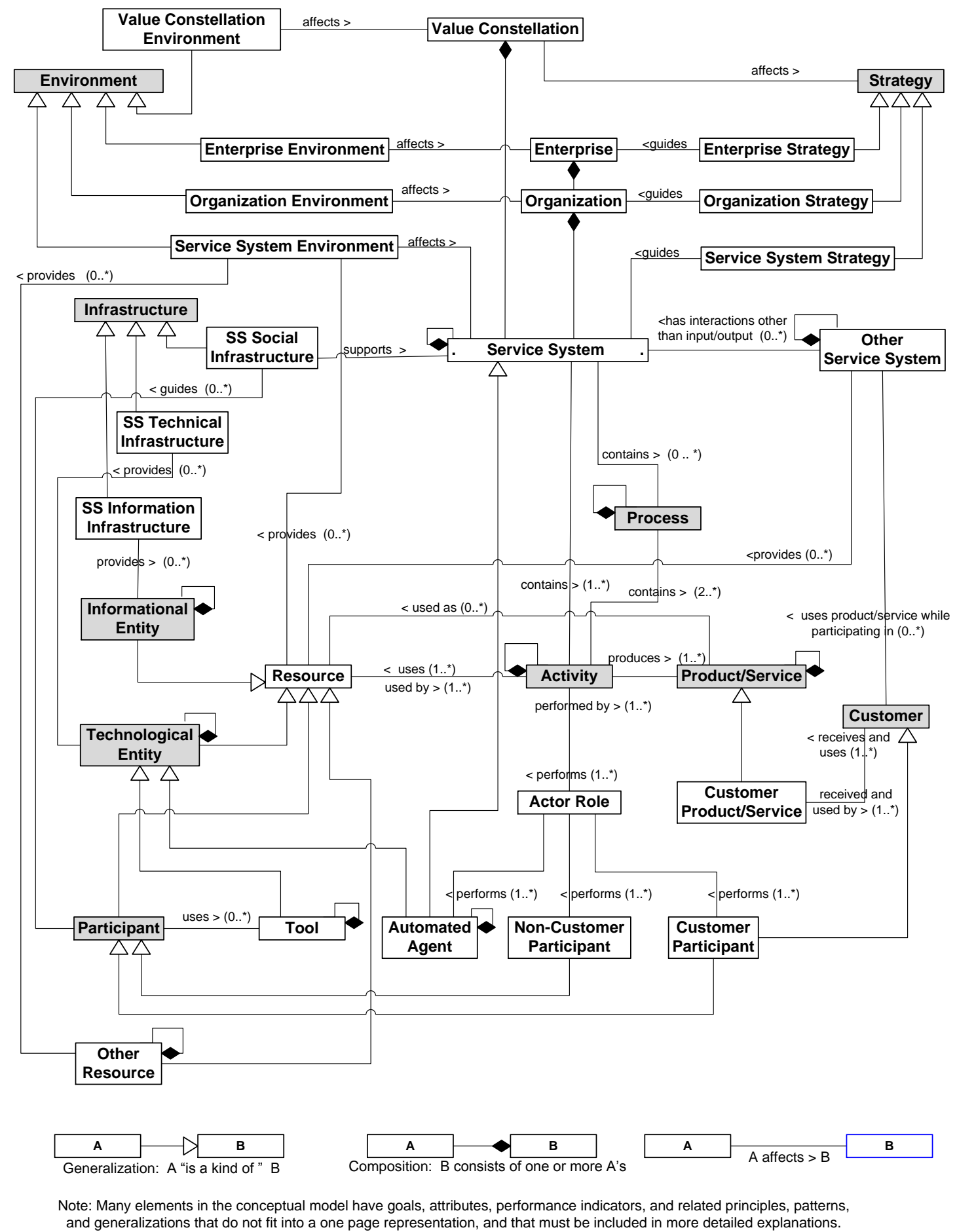

Figure 2. Metamodel for an operational service system within a value constellation 
Integrating service activities, service systems, and value constellations. The metamodel for service system analysis and design in Figure 2 covers three levels:

- service activities: methods and other details of specific service activities within service systems

- service systems as a whole, and their immediate relationships to and interactions with their customers and other systems that affect them

- value constellations: representing the role of a service system within broader value constellations.

The revision of the work system metamodel (Alter 2010a) that produced the service system metamodel in Figure 2 started with terminology changes, such as replacing the term work system and its abbreviation WS with the term service system and its abbreviation SS. Value constellation and value constellation environment were inserted at the top center of the metamodel. The metamodel says that a value constellation consists of one or more service systems, that a value constellation's environment affects the value constellation, that a value constellation's environment is part of the environment that might be considered when designing a service system, and that the value constellation might affect strategy at any of three levels: enterprise strategy, organization strategy, and service system strategy. A value constellation is assumed not to have a strategy because it consists of many semi-independent service systems that are not centrally controlled and that will change and evolve based on their owners' priorities.

Resources, structure, and intention. Figure 2 is organized to emphasize the interplay of resources, structure, and intentions. In general, the metamodel is laid out with resources on the left side, structural and operational elements in the middle, and elements related to intention on the right. The central elements in the metamodel are the service system itself (upper middle), activities that it performs (lower middle), and relevant value constellations (top middle).

Resources for a service system include participants, technological entities, informational entities, and other resources used by activities. Non-human resources might be produced by previous activities within the service system, or might come from other service systems, from the environment, or from any of three components of the infrastructure. The entity type "other resources" refers to noteworthy resources that are not informational entities, technological entities, or human participants. Examples include office buildings, transportation equipment, and natural resources such as a sunny climate, which might be very important for service systems in a resort hotel.

Structure starts with the value constellation, enterprise, and organization. Value constellations contain a number of service systems. Value constellations constitute part of a service system's environment and affect the strategies of the enterprise, organization, and service system itself. Organizations consist of service systems that may or may not include a well-defined process but that must contain at least one activity. Each activity is performed by one or more actor roles including noncustomer participant, customer participant, and automated agent.

Concepts related to intentions that are visible in the metamodel include product/service, customer, and strategy. Strategies summarize intentions for using resources to produce products/services. Product/service and customer appear on the side for intention because the purpose of a service system is to produce products/services for its customers. Other concepts related to intentions such as goals, metrics, characteristics, and incentives are relevant to service systems but are not shown in Figure 2. Instead, they are treated as attributes of specific elements or relationships.

Impacts of other service systems. Research related to interactions between tasks or systems has studied topics such as task interdependency (Thompson 1967), coordination theory (Malone et al., 1999; Crowston et al. 2006), and loose coupling theory (Orton and Weick 1990). The most obvious interactions between service systems are related to inputs and outputs, i.e., receipt and consumption of resources provided by other service systems and the production of products/services for use by other customers associated with other service systems. The metamodel includes an entity type called "other service system" and other types of interactions (labeled as "interactions other than input/output") because such interactions may be important in designing service systems. Such interactions include sharing of human participants and other resources, various forms of interference that occur accidentally, and requirements that one service system may impose on another, either implicitly or explicitly (Alter 2010a; 2010b). 


\section{Example Illustrating Three Levels of Analysis and Design}

Within this paper's page limits it is impossible to explain the rationale for each representation choice in the metamodel, including naming of entity types and relationships between entity types. Since the elements of the work system framework were defined in Table 1 and since the metamodel specifies relationships that are reasonably clear, our next step is to illustrate how the metamodel can be used in the three levels that were mentioned earlier: service activities, service systems, and value constellations. We use a simplified example related to payment for medical services provided in a small medical clinic in the United States. This example is a combination of several different real world situations (e.g., Fuhrmans 2007; Emanuel 2011).

The example involves a medical clinic whose patients have medical insurance that covers at least part of most medical services. Different patients have different insurance policies from different insurance companies that cover different services and provide different levels of payment to different groups of physicians. After providing medical services for a patient, a doctor fills in a paper form identifying the services that were provided and the length of the office visit. In some, but not all cases, the doctor supplies industry-standard codes identifying specific services that were provided. In some cases the doctors "adjust" service codes based on known payment policies of specific insurance companies. In some cases they may not know the service codes or maybe unsure whether the services are covered by the patient's insurance. The clinic's billing specialists record this information using medical billing software. In unusual cases they may have difficulty figuring out which codes are applicable. At the end of each day the office sends the entire day's billing information to a recently formed billing company that was created as an intermediary between small clinics and large insurance companies. The billing company's medical billing specialists examine the information from the clinic, correct some bills, call for clarifications of other bills, and forward the adjusted bills to the insurance company. The insurance company's medical billing specialists decide whether each billed service is covered by the patient's insurance, and at what level of payment. Doctors and patients receive notifications of payments to doctors and additional amounts due from patients.

Consistent with all eight premises that were discussed earlier, the service system metamodel guides description of this situation at three levels:

- Value constellation. Analysts focusing on the highest level of overview are interested in the relevant value constellation, which consists of service systems including providing medical services at the clinic, creating initial bills at the clinic, inspecting and adjusting the bills at the billing company, and determining payments at the insurance company. The limited knowledge of the billing staffs in small clinics created the opportunity for billing companies to play a new intermediary role in the value constellation. It is possible that future legislation will expand, diminish, or eliminate the role of such intermediaries or of insurance companies.

- Service system. Analysts focusing on specific service systems within the value constellation can use the metamodel's description of a service system in terms of concepts such as process, activity, actor role, participant, informational entity, and technological entity.

- Service activity. Analysts focusing on each activity in detail can use the metamodel's guidance for identifying all resources that an activity uses and all products/services that it creates, some of which will be resources for subsequent activities.

Table 2 summarizes the value constellation as though it were a single service system. In looking at the value constellation in more detail, each of the steps listed in Table 2 under "major processes and activities" could be represented as a separate service system on its own right by identifying in more detail exactly how those processes and activities are performed. Successive decomposition of each of those service systems would eventually isolate totally automated subsystems that provide information or support decision making, thereby translating a general business-oriented view of the situation to the level of detail that programmers need in order to produce software. The metamodel treats the totally automated 
subsystems as automated agents that are service systems on their own right, and therefore can be described using the metamodel.

Since a central goal of the metamodel is to support analysis and design for service systems, we will illustrate use of the metamodel by explaining how it applies to the three levels of analysis and design that were mentioned earlier. Encompassing all three levels within an integrated metamodel has several important advantages. First, it encourages consideration of big picture issues and detail-oriented issues, instead of focusing on one and essentially ignoring the other. In addition, it provides an analytical decomposition path from the higher levels to the lower levels, plus the corresponding traceability back to the higher levels.

\begin{tabular}{|c|c|c|c|}
\hline \multicolumn{2}{|c|}{ Customers } & \multicolumn{2}{|c|}{ Products/Services } \\
\hline \multicolumn{2}{|c|}{$\begin{array}{l}\text { - Billing specialist at clinic (receives payment } \\
\text { decision) } \\
\text { - Patient (receives medical care and payment } \\
\text { decision) }\end{array}$} & \multicolumn{2}{|c|}{$\begin{array}{ll} & \text { Medical services for patient } \\
\text { - } & \text { Initial bill for services rendered } \\
\text { - } & \text { Adjusted bill produced by billing company } \\
\text { - } & \text { Payment decision by an insurance company } \\
\text { patient }\end{array}$} \\
\hline \multicolumn{4}{|c|}{ Major Processes and Activities } \\
\hline \multicolumn{4}{|c|}{$\begin{array}{l}\text { - Doctors provide medical services and fill in a paper form describing services rendered. } \\
\text { - Billing specialist at the clinic enters billing information using billing software. } \\
\text { - Billing specialist at the clinic sends a batch of bills to the billing company. } \\
\text { - Billing specialist at the billing company analyzes and revises bills based on knowledge of medical billing } \\
\text { terminology and practices of patient's insurance company. } \\
\text { - Billing specialist at the billing company transmits bill to insurance company } \\
\text { - Payment specialist at the patient's insurance company uses customized payment analysis software to analyze } \\
\text { bills and decide on payment to doctors and additional amount to be paid by patient. } \\
\text { - Payment specialist at the patient's insurance company notifies doctor's billing specialist and patient of } \\
\text { payment decision }\end{array}$} \\
\hline Participants & \multicolumn{2}{|c|}{ Information } & Technologies \\
\hline $\begin{array}{l}\text { - } \quad \text { Doctors } \\
\text { - } \quad \text { Patients } \\
\text { - Billing specialists at the clinic } \\
\text { - Billing specialists at the } \\
\text { billing company } \\
\text { - Payment specialists at the } \\
\text { insurance company }\end{array}$ & \multicolumn{2}{|c|}{$\begin{array}{l}\text { - } \quad \text { Patient's medical history } \\
\text { - } \quad \text { Description of services rendered } \\
\text { - } \quad \text { Coded description of services } \\
\text { rendered } \\
\text { - } \quad \text { Initial bill } \\
\text { - } \quad \text { Revised bill } \\
\text { - Provisions and coverage of } \\
\text { patient's insurance policy } \\
\text { - Payment decision }\end{array}$} & $\begin{array}{l}\text { - Paper medical records for } \\
\text { patients } \\
\text { E Electronic billing system at } \\
\text { clinic and billing company } \\
\text { Claim analysis software at } \\
\quad \text { insurance company }\end{array}$ \\
\hline
\end{tabular}

Level 1: environment, strategy, and value constellation. Analysis and design of service systems needs to consider environment and strategy on three levels, enterprise, organization (e.g., department), and service system, plus relevant value constellations and the environment within which those value constellations exist. The related entity types appear in the upper part of the metamodel. Information and insights about the environment and about internal competences and capabilities can be used to reconsider the strategy of the enterprise, the organization, and the service system itself, and to evaluate whether strategies on the three levels are aligned. At all three levels, those strategies include value propositions for customers of the enterprise, organization, and service system, respectively, and internal strategies for using resources to produce products/services, including the extent of co-production. For externally facing service systems, consideration of value constellations calls for clarity about this service system's role in 
each relevant value constellation and possibilities for playing that role more efficiently or effectively, perhaps by expanding or contracting that role. In the medical payments example, each enterprise in the value constellation is concerned about whether its operational roles might change, might be absorbed by other enterprises, or might disappear from the value constellation, as might happen with new health care legislation or regulations.

Level 2: big picture view of the service system. At a local level, a big picture view of the operation of a service system summarizes customer groups, primary products/services produced for those customer groups, processes and activities, participants, and information and technology that is used. Table 2 presented this type of summary for the simplified value constellation using the format of a "work system snapshot." (Alter 2006; 2008b) Similar tables can be produced for subsystems related to each of the steps in Table 2, such as the service system of producing the original bill at the clinic and the service system of deciding what to pay. Analysis at this level was pursued successfully in projects by MBA students discussed in Truex et al. (2010; 2011), which reported on observations related to 75 and then 301 management briefings, respectively. The briefings were written using a work system analysis template that was primarily at this second level of analysis. The template was organized around a work system snapshot and included a number of questions related to evaluating how well the work system was operating and how it might be improved. Notice that the work system snapshot is sufficient for understanding the scope of the system being summarized but does not specify essential details such as which information and technology are used for each step and what is produced by each step. Those details require the more focused representation outlined by the metamodel.

Level 3: service activities and other operational specifics. As illustrated by Table 3, a more detailed view is required to clarify specifics that must be understood in order to create and maintain an efficient and effective service system. The relevant entity types appear in the lower part of the metamodel, starting with activities, actor roles that perform each activity, customer participants, non-customer participants, and/or automated agents that play each role, resources that are used for each activity, product/services produced by each activity, and subsequent use of those product/services in subsequent activities within the service system or by the service system's customers outside of the service system. Analysis on this level of detail is necessary for decomposing a service system into subsystems, some of which may be totally automated. The third level brings the analysis and description closer to the types of details that can be represented in UML, the "unified modeling language" that is a standard for objectoriented analysis and design.

Table 3 assumes that each step in Table 2 is treated as an activity within a service system. For each step it shows the customer and non-customer participants, the informational entities and technological entities, and the products/services produced. Similar tables can be produced by expanding each activity as a subsystem, a separate service system that can be summarized using the same type of table. The detailed flow of logic (e.g., forks and joins) can be represented as conditional activities or as subordinate subsystems.

\begin{tabular}{|c|c|c|c|c|c|}
\hline Activity & $\begin{array}{l}\text { Customer } \\
\text { participants }\end{array}$ & $\begin{array}{l}\text { Non-customer } \\
\text { participants }\end{array}$ & $\begin{array}{l}\text { Informational } \\
\text { entities }\end{array}$ & $\begin{array}{l}\text { Technological } \\
\text { entities }\end{array}$ & Product/services \\
\hline $\begin{array}{l}\text { Provide medical } \\
\text { services }\end{array}$ & Patient & Doctor & $\begin{array}{l}\text { * Patient's medical } \\
\text { history } \\
* \text { Current } \\
\text { symptoms }\end{array}$ & $\begin{array}{l}\text { Any technology } \\
\text { used in } \\
\text { providing } \\
\text { service }\end{array}$ & Diagnosis \\
\hline $\begin{array}{l}\text { Fill in paper } \\
\text { billing forms }\end{array}$ & & Doctor & $\begin{array}{l}\text { Description of } \\
\text { service rendered }\end{array}$ & Paper and pen & $\begin{array}{l}\text { Description of } \\
\text { service rendered }\end{array}$ \\
\hline $\begin{array}{l}\text { Enter billing } \\
\text { info into billing } \\
\text { software }\end{array}$ & & $\begin{array}{l}\text { Billing } \\
\text { specialist in } \\
\text { clinic }\end{array}$ & $\begin{array}{l}* \text { Description of } \\
\text { service rendered } \\
* \text { Coded }\end{array}$ & $\begin{array}{l}\text { Billing software } \\
\text { used by clinic }\end{array}$ & $\begin{array}{l}\text { Completed coding } \\
\text { of service by } \\
\text { doctor for patient }\end{array}$ \\
\hline
\end{tabular}




\begin{tabular}{|c|c|c|c|c|c|}
\hline & & & $\begin{array}{l}\text { description of } \\
\text { services } \\
* \text { Initial bill }\end{array}$ & & \\
\hline $\begin{array}{l}\text { Transmit bills to } \\
\text { billing company }\end{array}$ & & $\begin{array}{l}\text { Billing } \\
\text { specialist in } \\
\text { clinic }\end{array}$ & $\begin{array}{l}\text { Batch of initial } \\
\text { bills }\end{array}$ & $\begin{array}{l}\text { Billing software } \\
\text { used by clinic }\end{array}$ & $\begin{array}{l}\text { Transmission of } \\
\text { bills to billing } \\
\text { company }\end{array}$ \\
\hline $\begin{array}{l}\text { Analyze and } \\
\text { adjust bill }\end{array}$ & & $\begin{array}{l}\text { Billing } \\
\text { specialist in } \\
\text { billing company }\end{array}$ & $\begin{array}{l}\text { * Initial bill } \\
\text { * Patient's } \\
\text { insurance policy } \\
\text { * Revised bill }\end{array}$ & $\begin{array}{l}\text { Billing software } \\
\text { used by billing } \\
\text { company }\end{array}$ & $\begin{array}{l}\text { Revised bill for } \\
\text { service }\end{array}$ \\
\hline $\begin{array}{l}\text { Transmit } \\
\text { revised bill to } \\
\text { insurance } \\
\text { company }\end{array}$ & & $\begin{array}{l}\text { Billing } \\
\text { specialist in } \\
\text { billing company }\end{array}$ & $\begin{array}{l}\text { Revised bill for } \\
\text { service }\end{array}$ & $\begin{array}{l}\text { Billing software } \\
\text { used by billing } \\
\text { company }\end{array}$ & $\begin{array}{l}\text { Transmission of } \\
\text { revised bill to } \\
\text { patient's insurance } \\
\text { company }\end{array}$ \\
\hline $\begin{array}{l}\text { Decide on } \\
\text { payment }\end{array}$ & & $\begin{array}{l}\text { Payment } \\
\text { specialist at } \\
\text { insurance } \\
\text { company }\end{array}$ & $\begin{array}{l}\text { *Revised bill for } \\
\text { service } \\
\text { *Patient's } \\
\text { insurance policy }\end{array}$ & $\begin{array}{l}\text { Claim analysis } \\
\text { software used by } \\
\text { insurance } \\
\text { company }\end{array}$ & Payment decision \\
\hline $\begin{array}{l}\text { Transmit } \\
\text { payment } \\
\text { decision to } \\
\text { doctor and } \\
\text { patient }\end{array}$ & $\begin{array}{l}\text { * Doctor's } \\
\text { billing } \\
\text { specialist } \\
\text { * Patient }\end{array}$ & $\begin{array}{l}\text { Payment } \\
\text { specialist at } \\
\text { insurance } \\
\text { company }\end{array}$ & Payment decision & $\begin{array}{l}\text { Software for } \\
\text { transmitting } \\
\text { payment } \\
\text { decisions }\end{array}$ & $\begin{array}{l}\text { Transmission of } \\
\text { payment decision } \\
\text { to doctor and } \\
\text { patient }\end{array}$ \\
\hline
\end{tabular}

\section{Discussion}

The metamodel and the underlying definitions express a number of service science concepts in ways that represent progress for service science. The paper's coverage of the eight premises underlying the metamodel explained that some concepts expressed in the metamodel diverge from more established views in service science. The metamodel treats service systems as operational systems rather than as systems of economic exchange. Using that perspective leads to the three levels of analysis and design explained above. A possible challenge for proponents of the economic exchange view of service systems would involve creating a different metamodel based on economic exchange, and showing how that could be used for service system analysis and design. One of the advantages of the metamodel in Figure 2 is that the terms and relationships are relatively familiar and can be used to represent most service situations. This type of practicality was demonstrated by the example here and by previously mentioned results from Truex et al. $(2010 ; 2011)$, as mentioned above. The next stage in developing the metamodel would involve working through many examples to make sure that the different layers are useful and internally consistent when applied to complex examples.

\section{Actors, Products/services, and Resources}

The efficacy of the metamodel's representation of actors, product/services, and resources should be examined in both simple and complex situations because different representations might have been used in each case.

Actor roles. A product/service produced by an activity may be used by customer participants, noncustomer participants, and/or automated agents in subsequent activities, or may go to customers outside of the service system. The metamodel recognizes that two out of three types of actor roles are played by human participants whose personal characteristics (i.e., attributes of the entity type participant) include 
capabilities, competences, and incentives that could determine whether a service system operates according to intentions.

Products/services. Treating the output of a service activity as a product/service with no explicit distinction between products and services is consistent with the SDL view of products vs. services. Important attributes of product/services are characteristics that can be measured along separate dimensions that range from product-like to service-like (e.g., degree of customization and extensiveness of customer interaction). Those attributes and many other important characteristics are not visible in the representation of the metamodel in Figure 2, but are easy to include in computerized representations of the metamodel. Other attributes for product/service entities include directly measurable performance indicators and also subjective assessments such as quality or customer value.

Resources. The metamodel recognizes that each activity uses human, informational, technological, and/or other types of resources, and also that each activity produces informational, technological and/or other types of resources that may be used in other activities or that are received by customers outside of the service system.

\section{Co-production and co-creation of value.}

Co-production and co-creation of value are central topics in many views of service and service systems. Defining services as acts performed for the benefit of others helps in seeing that there are different degrees of co-production. Triggering action by requesting something (e.g., the definition of service by Sampson and Froehle (2006)) represents a minimalist version of co-production. Assume that each activity in a service system is performed by one or more actor roles involving customer participants or noncustomer participants. If a customer participant's request is the first of 20 activities and the next 19 are performed by non-customer participants, then we might say the service is coproduced even though only $5 \%$ of the steps involve co-production. From a service system design perspective, the much more interesting point about co-production is the design decision about how extensive co-production should be within a particular service system and how much responsibility customer participants should bear for which activities.

The concept of value co-creation goes beyond co-production because it concerns how and where customers capture value. As noted in Alter (2008b; 2010d), aspects of value creation may extend across an entire service system even when tangible products are produced, such as through easier ways of negotiating service commitments, preparing for service instances, specifying what is desired, and performing other activities related to the service. When a service (defined here as an activity performed for others) generates tangible things that are transferred to a customer, much of the value capture occurs when the customer uses those things, often in other service systems that have other participants and other goals. The metamodel assumes that that type of situation is outside of the boundaries of the service system that is being analyzed. The alternative would involve stretching the service system's boundary to include subsequent value capture by a range of different customers in different types of service systems or personal activities that they are involved with. Thus, the metamodel represents co-production of value in a useful way but does not deal with value capture that extends outside of the boundaries of the original service system.

\section{Relation to other topics often associated with service or service management}

Since the metamodel tries to cover any real world service system, it is useful to see whether it covers many of the ideas that are often associated with one or another aspect of service or service management. We will look at a number of topics that appeared as questions about the metamodel from previous discussions and critiques. Many other topics might have been chosen. In each case, assume that someone discussing the metamodel said, "yes, and what about $\mathrm{X}$ ?" where $\mathrm{X}$ is one of the following topics:

Time. The concept of time does not appear in Figure 2. The metamodel assumes that time can be treated implicitly through its appearance in attributes of activities (such as triggers, business rules, and metrics) and in attributes of product/services (such as availability dates and expiration dates). 
Service level agreements. The metamodel does not require SLAs since many service systems do not have SLAs. Where an SLA is relevant for a particular service system, the SLA would be treated as an attribute of the service system. The process of deciding on the SLA would be a management process that is separate from the service system in operation, just as the production of application software is different from the operation of a service system that uses the software.

Service quality. The metamodel does not contain an explicit concept of service quality. In any specific situation, attributes of specific product/services and specific activities would include the relevant metrics, some of which would be metrics for service quality.

Service climate. As with service quality, the metamodel does not contain an explicit concept of service climate, which can be treated as an attribute of several different entity types including service system, service system environment, organization environment, and enterprise environment.

Service encounters. The metamodel does not represent service encounter as a predefined concept. Service encounters occur in activities in which both customer participants and non-customer participants play a role or in which customer participants use resources provided by the service system owner. For example, activities in which customer participants make direct use of tools provided by the service provider (as in self-service use of an e-commerce website) might be considered service encounters because the tool represents the intention and competence of the service provider. The metamodel ignores service encounters that are not explicit activities in a service system, such as when a bank's loan officer acts friendly to a customer's child while the customer is in the bank.

Service blueprinting. The metamodel says nothing specific about service blueprinting, but potentially covers many of the basic concepts, such as the five components of a service blueprint (Bitner et al. 2008): customer actions, onstage contact employee actions, backstage contact employee actions, support processes, and physical evidence. The metamodel treats customer actions as activities performed by customer participants. It treats onstage and backstage contact employee actions as activities performed by non-customer participants. In many situations it would treat support processes as processes and activities in other service systems within the same value constellation. Physical evidence at each step would be an attribute of the related activity or of a particular product/service that is produces. Concepts such as the line of interaction, line of visibility, and line of internal interaction could be inferred in some situations but not in others. For example, specific activities that have both customer participants and noncustomer participants would typically be above the line of the interaction in a service blueprint.

Best practices. The metamodel uses the concepts process and activity to describe whatever practices occur in a service system. It expresses no view about whether those practices are "best practices" for any particular situation or for any larger class of similar situations. In general, the thinking underlying the metamodel views "best practices" as a marketing claim by vendors and consultants who often cannot know situation-specific issues, requirements, and constraints that may be unique to a particular service system in a particular setting. (e.g., see Wagner et al. 2006)

IT service management. The metamodel says nothing in general about disparate groups of service systems that often appear under umbrella headings such as IT service management. The metamodel could be applied to incident management, access management, release and deployment management or any of the other processes that are generally included in IT service management (e.g., those listed in itSMF 2007). It provides a way to think about each of those processes in service system terms, thereby demonstrating that the successful operation of the process involves not only the idealized definition of the process, but also situational factors such as characteristics of the participants and availability of key resources.

Enterprise architecture. The metamodel does not contain the concept of enterprise architecture because enterprise architecture is often far removed from the operational service systems that the metamodel focuses on. For example, assume that a multinational corporation's remote office in a city in South America wanted to use the metamodel to design a new service system for dispatching service technicians. Service analysts or designers would have to consider the relevant environment and the available infrastructure, but it is doubtful that they would have to consider a complete enterprise architecture. 
At the more limited level of service system architecture, the metamodel could potentially interface with many of the tools that are associated with enterprise architecture, such as ArchiMate (from the Open Group), the IT architecture ecosystem (from the Object Management Group), Business Process Modeling Notation (BPMN, from the Object Management Group), component business modeling (from IBM), event-driven process chain (from ARIS), and others. A separate research project would be required to work out the interfaces, overlaps, and disconnects in each case.

Decomposition within service systems. The metamodel treats roles of participants and of automated agents in a somewhat symmetrical manner, thereby facilitating the creation and use of tools for tracing the decomposition of service systems as part of analysis and design processes. That decomposition can be done in many different ways depending upon the goals and interests of the person doing the decomposition. For example, an IT professional might want to decompose the service system to isolate completely automated activities that might involve reuse of existing automated IT services or creation of new IT services. Someone interested in decision making might decompose a service system to isolate key decisions that have an important impact on the service system's performance. In either case, the decomposition would have to identify which activities belong in which subsystem. The resources produced and used by each activity within the original service system could be the basis of an initial test of whether the decomposition lost anything, since the production and/or use of each resource would still occur somewhere in the subsystems or would be replaced by the production and/or use of resources that are subdivided differently. The structure of the metamodel and the accommodation for isolating automated agents supports that type of decomposition.

Techniques and tools. One of the goals of the original metamodel in Alter (2010a) was to inspire a set of easily used tools in the form of tables based on links in the metamodel. Such tables devote one column to a specific entity type in the metamodel (e.g., activity, participant, or informational entity within a service system) and devote another column or several columns to directly related entity types or attributes. Typical tables might include participants in all activities at a particular level of decomposition, informational entities used by each activity, or a set of characteristics or metrics related to activities, informational entities, or participants. (Alter, 2008b). Use of such tables might lead to a new type of front end to rigorous modeling tools such as UML and BPMN that specify details more precisely, including detailed flow logic. It is possible to extend those tables to develop hierarchy-oriented tools that traverse different levels of decomposition. Those tools might incorporate guidelines for successive decomposition based in part on system decomposition guidelines in the computer science literature (for technical artifacts), in the organization literature (for departmentation and division of labor), and possibly in other literatures.

\section{Conclusion}

This paper started by questioning whether the new discipline of service science is coming to premature closure concerning a widely repeated assertion that service dominant logic is the foundation of service science. This paper presented an alternative perspective on service systems through a metamodel based on concepts and premises that are unique in a number of ways. The underlying definition of service is consistent with the more complex SDL definition of service, but different from many definitions of service in terms of characteristics that apply to some services but not to others. The metamodel was designed to traverse three levels of analysis and design in order to integrate concepts at those three levels.. Except in initial explorations and discussions posed broadly in terms of mission statements and value propositions, it would be risky to analyze or design real world service systems without considering most of the entity types in the metamodel.

This paper's contributions to service science started with comments and clarifications concerning basic concepts such as service, service system, customer, product/service, co-production and co-creation of value, actor roles, resources, symmetrical treatment of automated and non-automated service systems, and the relationship between SDL and service systems. Many articles have discussed these topics 
individually. Few if any have tied them together using an integrated metamodel. In addition, the way in which the metamodel was used to summarize and unravel the example creates a challenge for SDL or any other comprehensive view of service. How would SDL unravel this example? What questions would it lead an analyst to ask, and would those questions be helpful for practical analysis and design efforts in this type of situation?

Limitations. Although this paper's ideas and the metamodel that integrates them represent progress for service science, a number of limitations should be mentioned. The metamodel is a theoretical construction whose precision and usefulness have only been tested in hypothetical examples and informal inspection of many small case studies. The metamodel spans three levels of discussion but does not go to the level of detailed workflow logic that is included in formal modeling tools.

The metamodel identifies topics that should be considered in service system design, but does not provide a process for design or innovation. The work system life cycle model (Alter 2006; 2008a; 2008b) addresses part of that issue by outlining an iterative process through which work systems (almost all of which are service systems, as noted earlier) evolve over time through a combination of planned change (formal projects) and emergent change (incremental adaptations and workarounds). Ideas from the work system life cycle model might be combined with ideas from the literature on product and service design and innovation to create a better way of visualizing different paths for service design and innovation. Beyond this paper's scope, it would be interesting to analyze design and innovation processes from the literature to see which parts of the metamodel they consider and which parts they ignore.

This paper contributes to discussions of fundamental issues related to service, service systems, and service system analysis and design. Great progress has occurred on many fronts in recent years. There are many ideas, many viewpoints, many interesting examples, and many ambitions. This paper contributes by integrating ideas in a way that has not been presented in the past and that could be the basis of future theoretical developments and empirical research.

\section{References}

Alter, S. 2006. The Work System Method: Connecting People, Processes, and IT for Business Results, Larkspur, CA: Work System Press.

Alter, S. 2008a. Defining Information Systems as Work Systems: Implications for the IS Field. European Journal of Information Systems, 17(5), 448-469.

Alter, S. 2008b. Service System Fundamentals: Work System, Value Chain, and Life Cycle, IBM Systems Journal, 47(1), 71-85.

Alter, S 2008c Service System Innovation. pp. 61-80 in Barrett M, Davidson E, Middleton C, DeGross J. (eds.) Proceedings of IFIP 8.6 Conference, Information Technology in the Service Economy: Challenges and Possibilities for the 21st Century, Toronto, Canada, August. 2008, Boston: Springer.

Alter, S. 2010a. Bridging the Chasm between Sociotechnical and Technical Views of Systems in Organizations, Proceedings of ICIS 2010, the 31st International Conference on Information Systems.

Alter, S. 2010b. Including Work System Co-Existence, Alignment, and Coordination in Systems Analysis and Design, Proceedings of the Sixteenth Americas Conference on Information Systems, Lima, Peru.

Alter, S. 2010c. Service Systems and Service-Dominant Logic: Partners or Distant Cousins? Journal of Relationship Management, 9, pp. 98-115.

Alter, S. 2010d. Viewing Systems as Services: A Fresh Approach in the IS Field, Communications of the Association for Information Systems, 26(11), 195-224

Alter, S. 2011a. Making a Science of Service Systems Practical: Seeking Usefulness and Understandability while Avoiding Unnecessary Assumptions and Restrictions, pp. 61-72 in Demirkan, H., Spohrer, J., Krishna, V., The Science of Service Systems, Springer, New York, NY. 
Alter, S. 2011b. Metamodel for Service Design and Service Innovation: Integrating Service Activities, Service Systems, and Value Constellations, Proceedings of ICIS 2011, the 32nd International Conference on Information Systems.

Bitner, MJ, Ostrom, A., and Morgan, F. 2008. Service Blueprinting: A Practical Technique for Service Innovation, California Management Review, 50(3), 66-94.

Brown, A.W., Delbaere, M., Eeles, P., Johnston, S., and Weaver, R. 2005. Realizing Service-Oriented Solutions with the IBM Rational Software Development Platform, IBM Systems Journal 44(4),

Crowston, K., J. Howison, J. and Rubleske, J. 2006. Coordination Theory: A Ten Year Retrospective, in P. Zhang and D. Galletta, D. (eds.) Human-Computer Interaction in Management Information Systems - Foundations, M. E. Sharpe, Inc., Armonk, NY.

Emanuel, E.J. 2011. "Billions Wasted on Billing," New York Times, Nov. 12.

Feldman, M. and Pentland, B.T. 2003. "Reconceptualizing Organizational Routines as a Source of Flexibility and Change," Administrative Science Quarterly, 48(1), 94-118.

Fitzsimmons, J.A. and Fitzsimmons, M.J. 2006. Service Management, $5^{\text {th }}$ ed. NY, NY: McGraw-Hill.

Fuhrmans, V. 2007. "Billing Battle: Fights Over Health Claims Spawn a New Arms Race," Wall Street Journal, Feb. 14.

Grönroos, C., (2011) "Value creation in service logic: A critical analysis," Marketing Theory, 11(3), 279301.

Hill, T. P. 1977 . On goods and services. The Review of Income and Wealth, 23, 315-338.

IBM Research 2009 . Services Science, Management and Engineering, http://researchweb.watson.ibm.com/ssme/services.shtml. Accessed 4 Jan. 2012.

itSMF. 2007. An Introductory Overview of ITIL V3: A high-level overview of the IT Infrastructure Library. http://www.itsmfi.org/files/itSMF_ITILV3_Intro_Overview_0.pdf. Accessed 4 Jan. 2012

Kotler, P. and Keller, K. 2006. Marketing Management, $12^{\text {th }}$ ed., Upper Saddle River, NJ: Prentice Hall.

Maglio, P. P., Spohrer, J. 2008. Fundamentals of Service Science. Journal of the Academy of Marketing Science 36(1) 18-20.

Malone, T. W., et al. 1999. Tools for inventing organizations: Toward a handbook of organizational processes, Management Science, 45(3), 425-443.

Neely, A. 2008. Exploring the Financial Consequences of the Servitization of Manufacturing, Operations Management Research. 1(2), 103-118.

Normann, R. 2001. Reframing Business: When the Map Changes the Landscape. New York, NY: John Wiley \& Sons.

Normann, R. and Ramirez, R. 1994. Designing Interactive Strategy: From Value Chain to Value Constellation, Chichester, UK: John Wiley \& Sons.

Orton, J.D. and Weick, K.E. 1990. Loosely Coupled Systems: A Reconceptualization, The Academy of Management Review, 15(2), 203-223.

Porter, M.E. 1985. Competitive Advantage: Creating and Sustaining Superior Performance, The Free Press, USA.

Ramirez, R. 1999. Value Co-Production: Intellectual Origins and Implications for Practice and Research, Strategic Management Journal, 20, 49-65.

Sampson, S.E. and Froehle, C. M. 2006. Foundations and Implications of a Proposed Unified Services Theory. Production and Operations Management 15(2), 329-343.

Software Engineering Institute. 2010. CMMI® for Services, Version 1.3, Technical Report, CMU/SEI2010-TR-034, ESC-TR-2010-034.Spohrer, J. and Maglio, P. 2009. Service Science: toward a Smarter Planet. Service Engineering. ed. Karzwowsky \& Salvendy. Wiley, New York.

Spohrer, J., Golinelli, G.M., Piciocchi, P. Bassano, C. 2010. An Integrated SS-VSA Analysis of Changing Job Roles, Service Science 2(1/2) 1- 20.

Stabell, C.B., Fjeldstad, Ø.D. 1998. Configuring Value for Competitive Advantage: On Chains, Shops, and Networks, Strategic Management Journal, 19, 413-437. 
Star, S. L. and Bowker, G. C. 2002. "How to Infrastructure," in L. Lievrouw and S. Livingstone (Eds.), Handbook of the new media. London: SAGE, 151-162.

Tapscott, D., Ticoll, D., \& Lowy, A. 2000. Digital capital - harnessing the power of business webs, Boston, MA: Harvard Business School Press.

Truex, D., Alter, S., and Long, C. 2010. Systems Analysis for Everyone Else: Empowering Business Professionals through a Systems Analysis Method that Fits their Needs, Proceedings of 18th European Conference on Information Systems, Pretoria, South Africa.

Truex., D., Lakew, N., Alter, S., and Sarkar, S. 2011. Extending a Systems Analysis Method for Business Professionals, European Design Science Symposium, Leixlip, Ireland, Oct. 2011

Thompson, J.D. 1967. Organization in Action, Mc Graw- Hill, Chicago, IL.

Vargo, S.L. and Akaka, M.A. 2009. Service-Dominant Logic as a Foundation for Service Science: Clarifications, Service Science, (1:1), pp. 32-41.

Vargo, S.L. and Lusch, R.F. 2004a. Evolving to a New Dominant Logic for Marketing, Journal of Marketing, 68, 1-17.

Vargo, S.L. and Lusch, R.F. 2004b. The Four Service Marketing Myths, Journal of Service Research, (6:4), pp. 324-335.

Wagner, E. L., Scott, S. V. and Galliers, R. D. 2006. The creation of 'best practice' software: Myth, reality, and ethics, Information and Organization (16), pp. 251-275. 